7 Borghi-Silva A, Carrascosa C, Oliveira CC, et al. Effects of respiratory muscle unloading on leg muscle oxygenation and blood volume during high-intensity exercise in chronic heart failure. Am J Physiol Heart Circ Physiol 2008; 294 : H2465-H2472.

8 Chiappa GR, Queiroga F Jr, Meda E, et al. Heliox improves oxygen delivery and utilization during dynamic exercise in patients with chronic obstructive pulmonary disease. Am J Respir Crit Care Med 2009; 179: 1004-1010.

9 Laveneziana P, Valli G, Onorati P, et al. Effect of heliox on heart rate kinetics and dynamic hyperinflation during high-intensity exercise in COPD. Eur J Appl Physiol 2011; 111: 225-234.

10 Laveneziana P, Palange P, Ora J, et al. Bronchodilator effect on ventilatory, pulmonary gas exchange, and heart rate kinetics during high-intensity exercise in COPD. Eur J Appl Physiol 2009; 107: 633-643.

11 Berton DC, Barbosa PB, Takara LS, et al. Bronchodilators accelerate the dynamics of muscle $\mathrm{O}_{2}$ delivery and utilisation during exercise in COPD. Thorax 2010; 65: 588-593.

12 Witt JD, Guenette JA, Rupert JL, et al. Inspiratory muscle training attenuates the human respiratory muscle metaboreflex. J Physiol 2007; 584: 1019-1028.

\title{
Exercise oxygen uptake efficiency slope independently predicts poor outcome in pulmonary arterial hypertension
}

\author{
To the Editor:
}

Pulmonary arterial hypertension (PAH) remains a disabling and frequently lethal disease despite remarkable advances in treatment. Cardiopulmonary exercise testing (CPET) has proved a valuable tool to objectively quantify disease severity and estimate prognosis in these patients [1-3].

Exercise intolerance is characteristically multifactorial in PAH. Among its potential contributing mechanisms, increased ventilatory response, deranged pulmonary mechanics, peripheral muscle impairment and reduced oxygen delivery have been more widely investigated [1-5]. In this context, a CPETderived variable that conflates the effects of increased ventilation and poor $\mathrm{O}_{2}$ transfer and/or peripheral $\mathrm{O}_{2}$ utilisation is the $\mathrm{O}_{2}$ uptake efficiency slope (OUES) [6]. OUES is the slope of the linear relationship between $\mathrm{O}_{2}$ uptake $\left(V^{\prime} \mathrm{O}_{2}\right)$ and the logarithmic transformation of minute ventilation $\left(V^{\prime} \mathrm{E}\right)$ during rapidly incremental exercise, i.e. it aims to reflect how effectively $\mathrm{O}_{2}$ is extracted from the atmosphere and taken into the body as exercise progresses. We recently found that a combination of increased sub-maximal exercise $V^{\prime} \mathrm{E}$ as a function of carbon dioxide output $\left(V^{\prime} \mathrm{CO}_{2}\right)$ and reduced $\mathrm{O}_{2}$ delivery/utilisation (as suggested by shallow $V^{\prime} \mathrm{O}_{2}$-work rate relationship) were independent predictors of negative outcome in $\mathrm{PAH}$ of mixed aetiology [7]. These findings prompted the hypothesis that OUES would combine the prognostic information provided separately by those variables, thereby being the single predictor of poor outcome in our cohort.

In order to address this question, we revisited our dataset and contrasted OUES prognostic relevance with that of a range of resting and cardiopulmonary exercise responses to ramp-incremental cycle ergometry. In the previous report [7], we described results from a group of 84 patients in whom $16 \mathrm{PAH}-$ related deaths and two atrial septostomies were observed in a 5-year follow-up. In this present article, we extend these observations to 98 patients (70 females, 48 with idiopathic PAH and 50 with associated PAH) followed for up to 6.5 years, in whom $17 \mathrm{PAH}$-related deaths and four atrial septostomies were recorded. Receiver operating characteristic (ROC) curves were used to obtain the best cut-offs for prognostication. Cox proportional hazards and Kaplan-Meier cumulative survival analyses were performed following standard procedures. The statistical significance for all tests was $\mathrm{p}<0.05$.

We found that event-positive patients showed lower OUES than their counterparts (mean $\pm \mathrm{SD}$ $0.72 \pm 0.27 \mathrm{~L} \cdot \mathrm{min}^{-1}$ per $\log V^{\prime} \mathrm{E}$ versus $0.91 \pm 0.31 \mathrm{~L} \cdot \mathrm{min}^{-1}$ per $\left.\log V^{\prime} \mathrm{E}, \mathrm{p}<0.05\right)$. OUES was significantly related to prognosis in the univariate analysis (hazard ratio (HR) (95\% CI) $9.5(3.8-23.8), \mathrm{p}<0.01)$. The ROC curve analysis (area under the curve $0.688,95 \%$ CI $0.542-0.833 ; \mathrm{p}<0.01$ ) indicated a best OUES cutoff for prognostication of $0.56 \mathrm{~L} \cdot \mathrm{min}^{-1}$ per $\log V^{\prime} \mathrm{E}$. Among a range of resting and exercise variables, only peak $\mathrm{O}_{2}$ uptake $\left(V^{\prime} \mathrm{O}_{2}\right.$ peak), $V^{\prime} \mathrm{E} / V^{\prime} \mathrm{O}_{2}$ peak, change in $(\Delta) V^{\prime} \mathrm{E} / \Delta V^{\prime} \mathrm{CO}_{2}$ and $\Delta V^{\prime} \mathrm{O}_{2} / \Delta$ work rate were also predictors of poor outcome in the univariate analysis (HR (95\% CI) 2.4 (1.1-5.7), 8.4 (1.2-55), 4.2 $(1.5-11.6)$ and $6.8(2.6-17.3)$, respectively; $\mathrm{p}<0.05)$. Considering the close similarity between OUES and $V^{\prime} \mathrm{E} / V^{\prime} \mathrm{O}_{2}$ peak, multivariate regression analyses were performed using either of these variables. The 
prognostic power of OUES (HR (95\% CI) $4.63(1.38-15.5), \mathrm{p}=0.01)$ overcame that of $V^{\prime} \mathrm{O}_{2}$ peak and the slopes of $\Delta V^{\prime} \mathrm{E} / \Delta V^{\prime} \mathrm{CO}_{2}$ and $\Delta V^{\prime} \mathrm{O}_{2} / \Delta$ work rate in the final model (HR (95\% CI) 1.74 (0.69-4.37), $\mathrm{p}=0.23$; 2.20 (0.73-6.67), $\mathrm{p}=0.16$; and $2.24(0.70-7.11), \mathrm{p}=0.17$; respectively). $\Delta V^{\prime} \mathrm{O}_{2} / \Delta$ work rate, however, remained in the final model when $V^{\prime} \mathrm{E} / V^{\prime} \mathrm{O}_{2}$ peak was considered instead of OUES $(\mathrm{p}<0.05)$. In line with our hypothesis, therefore, OUES (but not $V^{\prime} \mathrm{E} / V^{\prime} \mathrm{O}_{2}$ peak) conflated the prognostic information provided by $\Delta V^{\prime} \mathrm{E} / \Delta V^{\prime} \mathrm{CO}_{2}$ and $\Delta V^{\prime} \mathrm{O}_{2} / \Delta$ work rate in our previous study (fig. 1). The same results were found when only mortality was considered the main outcome (data not shown).

Some preliminary considerations about the ventilatory-metabolic coupling during incremental exercise might be instructive to interpret our results. The ventilatory response to exercise is tightly coupled with the rate at which $\mathrm{CO}_{2}$ is exchanged at the lungs, i.e. $V^{\prime} \mathrm{CO}_{2}$. $V^{\prime} \mathrm{E}$ is needed to clear a given amount of $\mathrm{CO}_{2}$ when its arterial partial pressure is regulated at a lower set-point and the dead space fraction of the breath is increased, as found in PAH [1-5]. Progressive lactic acidosis (i.e. beyond the point at which the bicarbonate reserve is sufficient to fully tamponade $\mathrm{H}^{+}$) brings additional source of $V^{\prime}$ E stimuli at abnormally low levels of exertion in these patients. Right-to-left shunt through an open foramen ovale might also expose the carotid bodies to an extra burden of $\mathrm{H}^{+}$, which might sum up with variable levels of hypoxaemia. In fact, 21 (21\%) out of 98 patients showed evidence of an open foramen ovale during exercise. As expected, $\Delta V^{\prime} \mathrm{E} /$ $\Delta V^{\prime} \mathrm{CO}_{2}$ was greater and OUES lower in these patients compared with their counterparts $(82 \pm 25$ versus $52 \pm 12$ and $0.65 \pm 0.16 \mathrm{~L} \cdot \mathrm{min}^{-1}$ per $\log V^{\prime} \mathrm{E}$ versus $0.900 .29 \mathrm{~L} \cdot \mathrm{min}^{-1}$ per $\log V^{\prime} \mathrm{E}$, respectively). However, foramen ovale opening was not predictive of negative outcome in our sample. Additional sources of increasing nonmetabolic drive include excessive sympathetic drive, respiratory muscle weakness, ergoreceptor stimuli and increased pulmonary artery/right ventricle pressures [1-5]. These premises fully justify the notion that excessive $V^{\prime} \mathrm{E}$ response to $\mathrm{CO}_{2}\left(\Delta V^{\prime} \mathrm{E} / \Delta V^{\prime} \mathrm{CO}_{2}\right.$ slope $)$ is a valuable marker of disease severity and progression in PAH $[1-5,7]$.

OUES is substantially more complex to interpret than $\Delta V^{\prime} \mathrm{E} / \Delta V^{\prime} \mathrm{CO}_{2}$. Therefore, while $V^{\prime} \mathrm{E}$ is appropriately considered the dependent variable in $\Delta V^{\prime} \mathrm{E} / \Delta V^{\prime} \mathrm{CO}_{2}$, it is the independent parameter in OUES. Consequently, part of the information provided by OUES is intrinsically linked to the mechanisms regulating $\mathrm{CO}_{2}$ exchange. However, the rate at which $\mathrm{O}_{2}$ is taken into the body during the incremental phase of exercise (the dependent variable in OUES) is not limited by the ventilatory response in PAH but rather dependent upon cardiovascular, haematological and muscular adjustments [1-5]. In other words, abnormalities in any of the determinants of exercise hyperpnoea during exercise (either metabolic or nonmetabolic) plus derangements in systemic $\mathrm{O}_{2}$ transfer might reduce OUES. The inordinate high ventilatory response in PAH coupled with severe reductions $\mathrm{O}_{2}$ delivery/utilisation might explain why OUES seems to have a higher prognostic relevance in these patients than in chronic heart failure [8]. In fact, whereas OUES cut-offs to indicate poor prognosis in chronic heart failure were in the range of 1.3-1.5 L $\cdot \mathrm{min}^{-1}$ per $\log V^{\prime} \mathrm{E}$ [9], substantially lower values should be used in PAH $\left(0.56 \mathrm{~L} \cdot \mathrm{min}^{-1} \operatorname{per} \log V^{\prime} \mathrm{E}\right)$.

OUES calculation in PAH, however, may have some caveats that should be carefully considered. It should be noted that log transformation works particularly well in pronouncedly skewed data. If this is not the case, it may overcompensate a right-skewed data set and create a left-skewed one [10]. In practice, these caveats might promote nonlinearities and artificially increase OUES. This would be particularly anticipated in patients with high exercise $V^{\prime} \mathrm{E}$ from the start of the test who are able to sustain exercise long above the

FIGURE 1 Kaplan-Meier cumulative curves for pulmonary arterial hypertension-related events (death and atrial septostomy) according to oxygen uptake efficiency slope (OUES). The cut-off was determined by a receiver operating characteristic curve analysis. $\mathrm{p}<0.01$ by log-rank and Breslow tests. $V^{\prime} \mathrm{E}$ : minute ventilation.

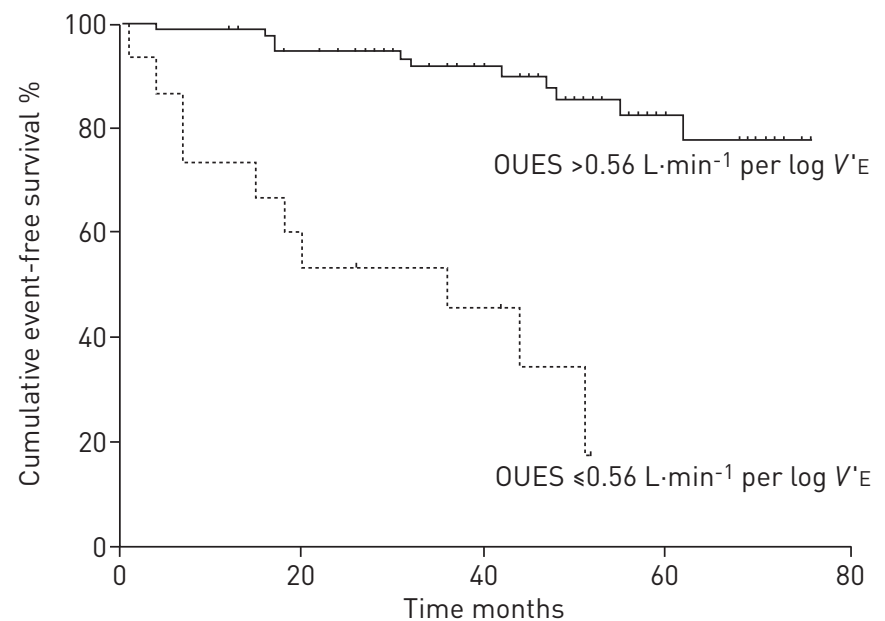


"anaerobic" threshold. In fact, NIEMEIJER et al. [11] found that the anaerobic threshold impacted on OUES linearity in chronic heart failure. Moreover, WILLIAMSON et al. [12] reported that OUES increased as exercise progressed, with a peak value of $V^{\prime} \mathrm{CO}_{2} / V^{\prime} \mathrm{O}_{2}$ of $\sim 1$. The best approach to calculate OUES in PAH patients with extremely elevated $V^{\prime} \mathrm{E}$ responses during exercise tests that are not too short (i.e. $8-12 \mathrm{~min}$ of incremental phase) remains to be determined. $V^{\prime} \mathrm{E} / V^{\prime} \mathrm{O}_{2}$ peak is a more straightforward variable and it might provide an interesting alternative to OUES. As a discrete, end-exercise variable, however, $V^{\prime} \mathrm{E} / V^{\prime} \mathrm{O}_{2}$ peak is expected to be more influenced by effort (or early exercise cessation due to intolerable dyspnoea) and degree of ventilatory response to lactic acidosis than OUES. Additional studies aiming to contrast the prognostic relevance of OUES and $V^{\prime} \mathrm{E} / V^{\prime} \mathrm{O}_{2}$ peak are therefore warranted.

In conclusion, OUES is a powerful prognostic index in patients with PAH. Although this variable is not usually available during CPET, most of the commercially available systems allow post-test data transformation making its calculation clinically friendly. Future investigations, however, should address whether restraining OUES estimation to specific time frames (e.g. below or above any inflection point) would further increase its prognostic relevance in $\mathrm{PAH}$.

0 @ERSpublications

Oxygen uptake efficiency slope is an independent predictor of poor outcome in PAH http://ow.ly/tjtmg

Roberta P. Ramos $^{1,2}$, Jaquelina S. Ota-Arakaki ${ }^{1,2}$, Maria Clara Alencar ${ }^{2}$, Eloara V.M. Ferreira ${ }^{1,2}$, Luiz Eduardo Nery ${ }^{2}$ and J. Alberto Neder ${ }^{2,3}$

${ }^{1}$ Pulmonary Vascular Group, Dept of Medicine, São Paulo School of Medicine (EPM), Federal University of São Paulo (UNIFESP), São Paulo, and ${ }^{2}$ Pulmonary Function and Clinical Exercise Physiology Unit, Division of Respiratory Diseases, Dept of Medicine, EPM, UNIFESP, São Paulo, Brazil. ${ }^{3}$ Division of Respiratory and Critical Care Medicine, Dept of Medicine, Queen's University, Kingston, ON, Canada.

Correspondence: J.A. Neder, Division of Respiratory and Critical Care Medicine, Dept of Medicine, Queen's University, 102 Stuart Street, Kingston, ON, Canada. E-mail: nederalb@gmail.com

Received: Sept 252013 | Accepted after revision: Nov 052013 | First published online: Dec 052013

Conflict of interest: None declared.

\section{References}

1 Arena R, Lavie CJ, Milani RV, et al. Cardiopulmonary exercise testing in patients with pulmonary arterial hypertension: an evidence-based review. J Heart Lung Transplant 2010; 29: 159-173.

2 Deboeck G, Scoditti C, Huez S, et al. Exercise testing to predict outcome in idiopathic versus associated pulmonary arterial hypertension. Eur Respir J 2012; 40: 1410-1419.

3 Mainguy V, Malenfant S, Neyron AS, et al. Repeatability and responsiveness of exercise tests in pulmonary arterial hypertension. Eur Respir J 2013; 42: 425-434.

4 Sun XG, Hansen JE, Oudiz RJ, et al. Exercise pathophysiology in patients with primary pulmonary hypertension. Circulation 2001; 104: 429-435.

5 Laveneziana P, Garcia G, Joureau B, et al. Dynamic respiratory mechanics and exertional dyspnoea in pulmonary arterial hypertension. Eur Respir J 2013; 41: 578-587.

6 Baba R, Nagashima M, Goto M, et al. Oxygen uptake efficiency slope: a new index of cardiorespiratory functional reserve derived from the relation between oxygen uptake and minute ventilation during incremental exercise. $J A m$ Coll Cardiol 1996; 28: 1567-1572.

7 Ferreira EV, Ota-Arakaki JS, Ramos RP, et al. Optimizing the evaluation of excess exercise ventilation for prognosis assessment in pulmonary arterial hypertension. Eur J Prev Cardiol 2013 [In press DOI: 10.1177/ 2047487313494293].

8 Arena R, Myers J, Hsu L, et al. The minute ventilation/carbon dioxide production slope is prognostically superior to the oxygen uptake efficiency slope. J Card Fail 2007; 13: 462-469.

9 Akkerman M, van Brussel M, Hulzebos E, et al. The oxygen uptake efficiency slope: what do we know? Cardiopulm Rehabil Prev 2010; 30: 357-373.

10 Bland JM, Altman DG, Rohlf FJ. In defense of logarithmic transformations. Stat Med 2013; 32: 3766-3768.

11 Niemeijer VM, Veer MV, Schep G, et al. Causes of nonlinearity of the oxygen uptake efficiency slope: a prospective study in patients with chronic heart failure. Eur J Prev Cardiol 2014; 21: 347-353.

12 Williamson W, Fuld J, Westgate K, et al. Validity of reporting oxygen uptake efficiency slope from submaximal exercise using respiratory exchange ratio as secondary criterion. Pulm Med 2012; 2012: 874020. 